\title{
Propagation of Himalayan maple (Acer caesium Wall.) through seed and softwood cuttings
}

\section{P. A. Sofi", Sajad A. Bhat, T. H. Masoodi, M. A. Islam, G. M. Bhat and A. R. Malik}

Faculty of Forestry, Sher-e-Kashmir University of Agricultural Sciences and Technology of Kashmir, Benhama, Ganderbal-191201 (J\&K), INDIA

*Corresponding author. E-mail: parvezsofi1 @gmail.com

Received: November 09, 2015; Revised received: April 19, 2016; Accepted: July 15, 2016

Abstract: Propagation of Himalayan maple (Acer caesium Wall.) through seed and softwood cuttings was investigated to standardize nursery techniques for mass production of the species. The seedlings were raised from viable seeds in different containers filled with different combinations of growing media. Vegetative propagation of softwood cuttings was carried out by treating with different combinations of IBA and Willow leachate of different durations. The statistical analysis revealed the differential behaviour of various nursery stocks with respect to survival, growth and biomass. The growing media soil:sand:vermicompost (2:1:2) and container (root trainer $300 \mathrm{cc}$ ) showed maximum germination $(61.00 \%)$, seedlings height $(35.17 \mathrm{~cm})$, collar diameter $(5.07 \mathrm{~cm})$, shoot:root ratio $(1.24)$ and survival percentage (76.33\%). Conversely, the cuttings treated with IBA @ 8000 ppm showed maximum sprouting (74.50\%), rooting $(66.75 \%)$, length of longest root $(14.65 \mathrm{~cm})$, no. of roots per cutting $(33.00 \%)$, shoot length $(13.90 \mathrm{~cm})$ and survival percentage (41.50\%). Hence, the seeds of the species should be grown in Rot trainer of $300 \mathrm{cc}$ having soil:sand:vermicompost $(2: 1: 2)$ to get good quality planting materials. However, the softwood cuttings should be given treatments with IBA @ 8000 ppm for mass production of plants vegetatively.

Keywords: Acer caesium, IBA, Propagation, Root trainer, Seed, Softwood, Willow leachate

\section{INTRODUCTION}

Himalayan maple (Acer caesium Wall.) is one of the important unevenly distributed deciduous trees of Kashmir belonging to family Aceraceae or maple family (Luna, 2005). It is native to China, India (Himachal Pradesh, J \& K, Uttaranchal, and U.P), Nepal, and Pakistan at altitudes from 2000 to $3500 \mathrm{~m}$ (Van Geldren et al., 2010). It grows on north-facing slopes upto 25 meter in height and preferably on the moist soil. Basically, the word "Acer" derives from a Latin word meaning "sharp", referred to the "sharp points on the leaves" and "caesium" means "Light blue", shoots and young leaves gives a blueish-grey appearance. The tree is an economically important tree species, not only for its high quality wood, but also because it is mostly used as ornamental trees by home owners and municipalities (Ghosh, 1977). The maple leaf is used in flag of "Canada", as it is a symbol of strength and endurance and chosen as the national tree of many countries. The timber seasons well but should be converted shortly after felling otherwise a grey-red discolouration and honey-comb cracking appears (Anonymous, 1983). The wood of the tree is used for carving bowls and cups, making plates, furniture, turnery articles, frames, boarding and rifle (Anonymous, 1985). Juice extracted from bark is used in the treatment of muscular swelling, boils and pimples. Leaves are used in the packing of apples and root crops. Fruits are called as "whirlybirds" as they occur in distinctive pairs each containing one seed enclosed in a "nut let", children often call falling fruits "helicopters" due to the way that they spin when they fall. Despite intense socio-economic and cultural significance of the species, the mass propagation of the species remained a challenge for farmers, nursery growers and entrepreneur in Kashmir (Islam et al., 2015). Hence, production of quality planting materials on a large scale either from seeds or cuttings of the superior tree is imperative to fulfill the need.

Mass propagation by seeds is an effective and sometimes the only means of propagation (Meiners, 2005). Seed propagation offers the advantages of being cheap and simple, but it is only useful when genetic variation is acceptable (Brock et al., 2012). Successful regeneration of any species depends on its seed quality and quantity (Starr, 2011). However, the method of raising seedlings has a profound influence on the morphometric parameters of seedling viz. seedling height, shoot collar diameter and total dry weight throughout the growth period of seedling (Khali and Sharma, 2003). Vegetative propagation is used to produce a plant identical in genotype with mother plant (Roussy, 2014). It is most convenient, easiest and economical method of propagation for some important crops (Alsup, 2001). An efficient method of propagating Himalayan Maple by softwood cuttings could improve the availability 
and popularity of this promising species. The present study was therefore, undertaken to propagate Acer caesium through seeds and softwood cuttings to provide better seedlings and rooted cuttings for future afforestation by using genetic material from mature trees.

\section{MATERIALS AND METHODS}

The study was conducted at the Faculty of Forestry of this University located at Wadoora, Sopore, which is situated at $34^{0} 17^{\prime} \mathrm{N}$ latitude and $74^{0} 33^{\prime} \mathrm{E}$ longitude and 1524 meters above the mean sea level (Anon., 2011). The soil at the experimental station was siltyclay loam, non-saline with $\mathrm{pH} 7.3$ and contained $0.73 \%$ organic carbon, $272.5 \mathrm{~kg} /$ ha available $\mathrm{N}, 17.5$ $\mathrm{kg} / \mathrm{ha}$ extractable $\mathrm{P}$ and $249.6 \mathrm{~kg} / \mathrm{ha}$ available $\mathrm{K}$. The treatments consisted of six potting mixture using soil, sand and vermicompost as ingredients in different volume proportions and two container types, were tested to get best mixture and container type for production of quality seedling stock. The various potting mixture and their proportionate ingredients (soil:sand:vermicompost) used were in the ratio of 1:0:0 $\left(\mathrm{M}_{1}\right), 1: 1: 0\left(\mathrm{M}_{2}\right), 1: 1: 1\left(\mathrm{M}_{3}\right), 1: 1: 2\left(\mathrm{M}_{4}\right)$, 2:1:1 $\left(\mathrm{M}_{5}\right)$ and 2:1:2 $\left(\mathrm{M}_{6}\right)$. The potting mixture were placed in the perforated polybags of size $7 " \times 5$ " and root trainer of $300 \mathrm{cc}$ where, the viable seeds of Acer caesium were sown and seedlings were raised. The performance of seedlings in both the container types in terms of germination percentage, seedling height, collar diameter, shoot weight (fresh/dry), root weight (fresh/dry), shoot:root ratio and survival percentage during the growing season was recorded (Elfadl, 2013). Seedling height was measured using graduated scale and collar diameter was recorded through digital caliper (Brock et al., 2012). Shoot and root weight were recorded by top pan balance (ISTA, 1999).

In case of propagation through softwood cuttings of Acer caesium, the treatments were consisted of five concentrations of IBA viz., 2000, 4000, 6000, 8000 and 10,000 ppm and three willow leachate of 12, 24 and 36 hours. Softwood cuttings of the species of uniform size having $22 \mathrm{~cm}$ length and of pencil thickness were collected during February-March from well grown trees and bulked together. The cuttings then treated with the different concentrations of IBA and Willow leachate of different duration to induce rooting. The number of cuttings per treatment was 50 in 4 replications. Cuttings were dipped in 2000, 4000, 6000,8000 and 10,000 ppm of IBA for 10-15 seconds and in willow leachate of 12, 24 and 36 hours for 24 hours. The cuttings were given injury in the form of a ring at the lower portion to promote rooting. The performance of cuttings with different concentrations of IBA and Willow leachate of different duration were recorded in terms of sprouting percentage, rooting percentage, length of longest root, number of roots/ cutting, shoot height and survival percentage during the growing season as per Khali and Sharma (2003).

\section{RESULTS AND DISCUSSION}

Maximum germination percentage $(61.00 \%)$ was recorded in growing medium $\mathrm{M}_{6}$ which was followed by $\mathrm{M}_{4} \quad(58.50 \%), \quad \mathrm{M}_{5} \quad(51.16 \%), \mathrm{M}_{3} \quad(44.50 \%), \mathrm{M}_{2}$ (40.50\%) and $\mathrm{M}_{1}(37.50 \%)$ (Table 1). Among container types the maximum germination percentage $(50.88 \%)$ was recorded in root trainer $(300 \mathrm{cc})$ while, the minimum $(46.83 \%)$ was recorded in polybags of size $7 " \times 5$ ' . The seedling height was maximum $(35.17 \mathrm{~cm})$ in the growing medium $\mathrm{M}_{6}$ which was followed by $\mathrm{M}_{4}(31.82 \mathrm{~cm}), \mathrm{M}_{5}(29.28 \mathrm{~cm}), \mathrm{M}_{3}(21.96$ $\mathrm{cm}), \mathrm{M}_{2}(17.10 \mathrm{~cm})$ and $\mathrm{M} 1(15.16 \mathrm{~cm})$ (Table 1). The maximum seedling height $(25.90 \mathrm{~cm})$ was shown by container polybags whereas; minimum seedling height $(24.27 \mathrm{~cm})$ was recorded in the container root trainer of $300 \mathrm{cc}$. As regards, collar diameter the maximum (5.07 mm) was recorded in the growing medium $\mathrm{M}_{6}$ followed by $\mathrm{M}_{4}(4.23 \mathrm{~mm}), \mathrm{M}_{5}(3.60 \mathrm{~mm}), \mathrm{M}_{3}(3.33$ $\mathrm{mm}), \mathrm{M}_{2}(2.70 \mathrm{~mm})$ and $\mathrm{M} 1$ (2.29 mm) (Table 1). Among container types, the maximum $(3.65 \mathrm{~mm})$ was recorded in the root trainer $(300 \mathrm{cc})$ and the minimum was shown by polybags $(3.44 \mathrm{~mm})$.

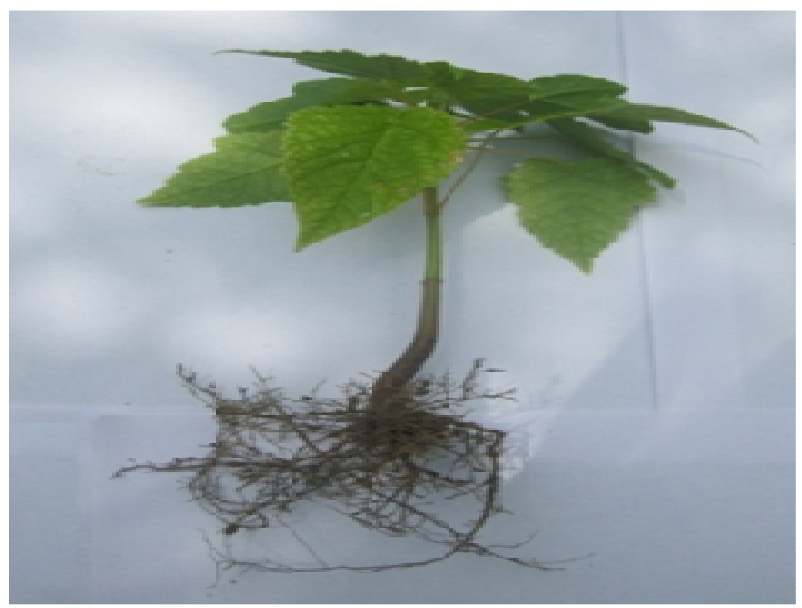

Plate 1. Root trainer raised seedling.

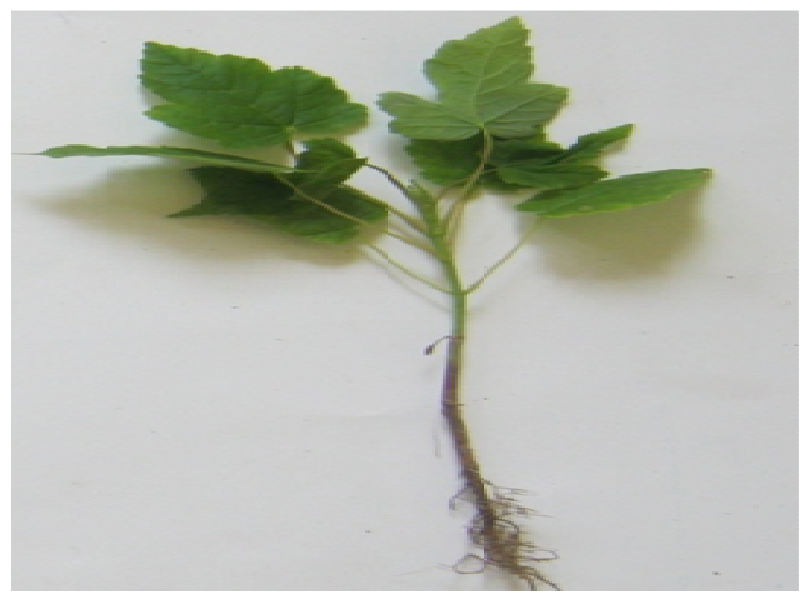

Plate 2. Polybag raised seedling . 


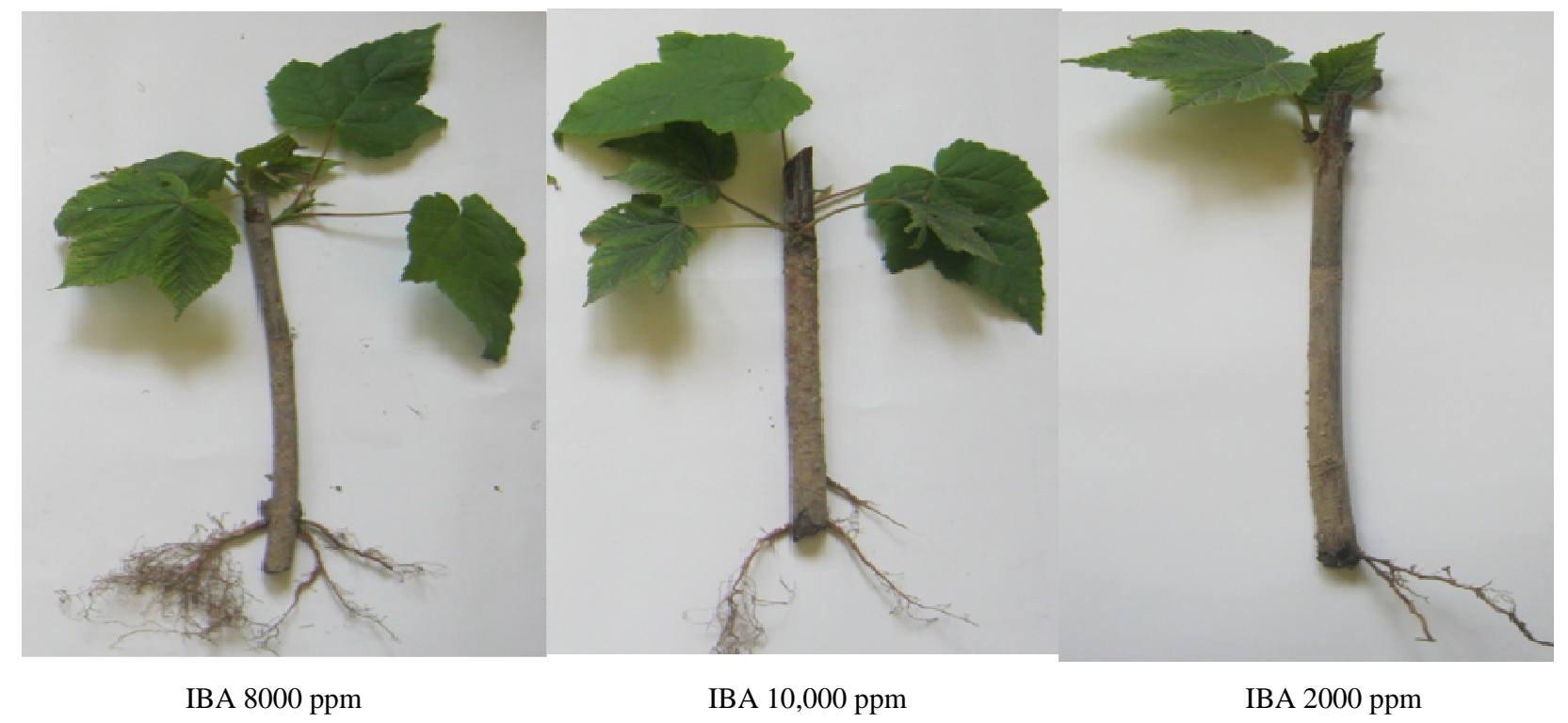

Plate 3. Cuttings of A. caesium treated with different IBA concentrations.

Table 1. Germination percentage, seedling height $(\mathrm{cm})$ and collar diameter $(\mathrm{mm})$ of seedlings in various containers with different growing media.

\begin{tabular}{|c|c|c|c|c|c|c|c|c|c|}
\hline \multirow[t]{2}{*}{ Media } & \multicolumn{3}{|c|}{ Germination percentage (\%) } & \multicolumn{3}{|c|}{ Seedling height $(\mathrm{cm})$} & \multicolumn{3}{|c|}{ Collar diameter $(\mathrm{mm})$} \\
\hline & $\begin{array}{l}\text { Root } \\
\text { trainer } \\
(300 \text { cc }) \\
\end{array}$ & $\begin{array}{l}\text { Polybags } \\
\text { (7" x 5") }\end{array}$ & Mean & $\begin{array}{l}\text { Root } \\
\text { trainer } \\
(300 \mathrm{cc})\end{array}$ & $\begin{array}{l}\text { Polybags } \\
\text { (7"x 5") }\end{array}$ & Mean & $\begin{array}{l}\text { Root } \\
\text { trainer } \\
(300 \mathrm{cc})\end{array}$ & $\begin{array}{l}\text { Polybags } \\
\text { (7"x 5") }\end{array}$ & Mean \\
\hline $\mathrm{M}_{1}$ & 38.00 & 37.00 & 37.50 & 14.88 & 15.45 & 15.16 & 2.37 & 2.22 & 2.29 \\
\hline $\mathrm{M}_{2}$ & 43.00 & 38.00 & 40.50 & 16.80 & 17.41 & 17.10 & 2.78 & 2.63 & 2.70 \\
\hline $\mathrm{M}_{3}$ & 46.00 & 43.00 & 44.50 & 20.75 & 23.18 & 21.96 & 3.47 & 3.19 & 3.33 \\
\hline $\mathrm{M}_{4}$ & 60.00 & 57.00 & 58.50 & 30.80 & 32.85 & 31.82 & 4.36 & 4.10 & 4.23 \\
\hline $\mathrm{M}_{5}$ & 54.33 & 48.00 & 51.16 & 28.69 & 29.86 & 29.28 & 3.73 & 3.48 & 3.60 \\
\hline $\mathrm{M}_{6}$ & 64.00 & 58.00 & 61.00 & 33.70 & 36.63 & 35.17 & 5.20 & 4.94 & 5.07 \\
\hline Mean & 50.88 & 46.83 & - & 24.27 & 25.90 & - & 3.65 & 3.44 & - \\
\hline & C.D. $(0.05)$ & \pm S.E. & & C.D. $(0.05)$ & \pm S.E. & & C.D. $(0.05)$ & \pm S.E. & \\
\hline Container & 0.051 & 0.017 & & 0.231 & 0.079 & & 0.165 & 0.056 & \\
\hline Media & 0.089 & 0.030 & & 0.401 & 0.137 & & 0.286 & 0.098 & \\
\hline $\begin{array}{l}\text { Container } \\
\text { x Media }\end{array}$ & 0.127 & 0.043 & & 0.568 & 0.195 & & N.S & 0.138 & \\
\hline
\end{tabular}

Regarding shoot: root ratio, the maximum ratio (1.24) was shown by the medium $\mathrm{M}_{6}$ which was followed by M4 (1.21), $\mathrm{M}_{5}$ (1.19), $\mathrm{M}_{3}(1.14), \mathrm{M}_{2}$ (1.11) and $\mathrm{M}_{1}$ (1.07) (Table 2$)$. The container polybag of size $\left(7^{\prime}\right.$ ' $\times$ 5") has shown the maximum shoot: root ratio (1.19) while it was minimum in the container root trainer 300 cc (1.12). The survival percentage was maximum (76.33\%) in the growing $\mathrm{M}_{6}$ followed by $\mathrm{M}_{4}(65.33 \%)$, $\mathrm{M}_{5}(61.16 \%), \mathrm{M}_{3}(54.16 \%), \mathrm{M}_{2}(46.33 \%)$ and $\mathrm{M}_{1}$ $(40.66 \%)$ (Table 2). Container type also showed significant difference on the survival of seedlings in the nursery having maximum $(59.44 \%)$ in container root trainer $(300 \mathrm{cc})$ and minimum $(55.22 \%)$ in container polybag $\left(7^{\prime}, \times 5\right.$ ' $)$. The container root trainer is significantly superior over the container polybag (Plate 1-2). The interaction effect of growing media and container type showed non-significant results for shoot: root ratio. The potting mixtures have significant effect on the growth and development of the seedlings in terms of germination percentage, seedling height, collar diameter, shoot weight (fresh/dry), root weight (fresh/dry), shoot: root ratio and survival percentage. The best performance with regard to these parameters is shown by the growing medium $\mathrm{M}_{6}$ having soil, sand and vermicompost in the ratio of $2: 1: 2$. This potting medium exhibited germination percentage of $61.00 \%$, seedling height $(35.17 \mathrm{~cm})$, collar diameter $(5.07 \mathrm{~mm})$, shoot weight fresh $(3.52 \mathrm{~g})$, shoot weight dry $(1.65 \mathrm{~g})$, root weight fresh $(3.02 \mathrm{~g})$, root weight dry $(1.33 \mathrm{~g})$ and survival percentage $(73.33 \%)$ which differed significantly from the media $\mathrm{M}_{1}, \mathrm{M}_{2}, \mathrm{M}_{3}, \mathrm{M}_{4}$ and $\mathrm{M}_{5}$ having soil, sand and vermicompost in the ratio of 1:0:0, $1: 1: 0,1: 1: 1,1: 1: 2$ and $2: 1: 1$ respectively. Sofi and Bharadwaj (2007) showed that the growth and biomass of Cedrus deodara was observed best in potting mixture of soil, sand and FYM in the ratio of 1:1:3. These results are in agreement with the findings of Bhardwaj et al. (1996) in Pinus roxburghii, Pyarelal and Karna- 
P. A. Sofi et al. / J. Appl. \& Nat. Sci. 8 (3): 1235 - 1240 (2016)

Table 2. Shoot:Root ratio and survival percentage of seedlings in various containers with different growing media.

\begin{tabular}{|c|c|c|c|c|c|c|}
\hline \multirow[t]{2}{*}{ Media } & \multicolumn{3}{|l|}{ Shoot:Root ratio } & \multicolumn{3}{|c|}{ Survival percentage (\%) } \\
\hline & Root trainer $(300 \mathrm{cc})$ & $\begin{array}{l}\text { Polybags } \\
\text { (7”x 5") }\end{array}$ & Mean & $\begin{array}{l}\text { Root trainer }(300 \\
\mathrm{cc})\end{array}$ & $\begin{array}{l}\text { Polybags } \\
(7 " \times 5 ")\end{array}$ & Mean \\
\hline $\mathrm{M}_{1}$ & 1.05 & 1.09 & 1.07 & 41.33 & 40.00 & 40.66 \\
\hline $\mathrm{M}_{2}$ & 1.06 & 1.16 & 1.11 & 48.33 & 44.33 & 46.33 \\
\hline $\mathrm{M}_{3}$ & 1.07 & 1.21 & 1.14 & 55.66 & 52.66 & 54.16 \\
\hline $\mathrm{M}_{4}$ & 1.19 & 1.24 & 1.21 & 67.33 & 63.33 & 65.33 \\
\hline $\mathrm{M}_{5}$ & 1.17 & 1.21 & 1.19 & 63.00 & 59.33 & 61.16 \\
\hline $\mathrm{M}_{6}$ & 1.20 & 1.27 & 1.24 & 81.00 & 71.66 & 76.33 \\
\hline \multirow[t]{2}{*}{ Mean } & 1.12 & 1.19 & - & 59.44 & 55.22 & - \\
\hline & C.D. ${ }_{(0.05)}$ & \pm S.E. & & C.D. ${ }_{(0.05)}$ & \pm S.E. & \\
\hline Container & 0.035 & $\overline{0} .012$ & & 0.083 & 0.028 & \\
\hline Media & 0.060 & 0.020 & & 0.144 & 0.049 & \\
\hline Container x Media & N.S & 0.029 & & N.S & 0.069 & \\
\hline
\end{tabular}

Table 3. Effect of IBA and Willow leachate on vegetative propagation of A. caesium.

\begin{tabular}{lllllll}
\hline Treatment & $\begin{array}{l}\text { Sprouting } \\
(\%)\end{array}$ & Rooting $(\%)$ & $\begin{array}{l}\text { Length of long- } \\
\text { est root }(\mathrm{cm})\end{array}$ & $\begin{array}{l}\text { No. of roots/ } \\
\text { cutting }\end{array}$ & $\begin{array}{l}\text { Shoot length } \\
(\mathrm{cm})\end{array}$ & Survival (\%) \\
\hline Control & 55.50 & 0.00 & 0.00 & 0.00 & 0.00 & 0.00 \\
IBA 2000 ppm & 60.75 & 20.75 & 3.60 & 3.25 & 3.95 & 4.50 \\
IBA 4000 ppm & 69.75 & 40.75 & 4.70 & 7.25 & 8.12 & 15.75 \\
IBA 6000 ppm & 73.00 & 57.75 & 10.67 & 17.25 & 10.35 & 27.75 \\
IBA 8000 ppm & 74.50 & 66.75 & 14.65 & 33.00 & 13.90 & 41.50 \\
IBA 10000 ppm & 73.75 & 65.00 & 13.17 & 27.25 & 9.40 & 33.00 \\
Willow leachate 12 hour & 71.75 & 0.00 & 0.00 & 0.00 & 0.00 & 0.00 \\
Willow leachate 24 hour & 72.25 & 0.00 & 0.00 & 0.00 & 0.00 & 0.00 \\
Willow leachate 36 hour & 73.75 & 0.00 & 0.00 & 0.00 & 0.00 & 0.00 \\
tS.E. & 0.046 & 0.046 & 0.135 & 0.722 & 0.154 & 0.066 \\
C.D.(0.05) & 0.136 & 0.136 & 0.395 & 2.121 & 0.453 & 0.194 \\
\hline
\end{tabular}

taka (1993) in Quercus leucotrichophora, and Bahuguna et al. (1987) in Acaia albida. Srivastava et al. (1998) showed potting mixture of compost, sand and soil in the ratio of 2:1:2 as best for raising quality seedling of Eucalyptus hybrid. Omokhua et al. (2015) shown that the germination percentage of Terminalia ivorensis improved significantly with sowing media especially sawdust and topsoil and hence, the use of sawdust and topsoil as sowing media for large scale propagation of the species is recommended. Atik and Yllmaz (2014) showed that vermicompost treatment contributed positively to the development of scots pine (Pinus sylvestris L.) seedlings taken from seven different origins. The root trainer $300 \mathrm{cc}$ exhibited maximum germination percentage $(50.88 \%)$, collar diameter $(3.65 \mathrm{~mm})$, fresh shoot weight $(2.19 \mathrm{~g})$, dry shoot weight $(1.06 \mathrm{~g})$, fresh root weight $(1.99 \mathrm{~g})$, dry root weight $(0.92 \mathrm{~g})$ and survival percentage $(59.44 \%)$. In case of seedling height and shoot: root ratio highest performance was shown by polybags of size 7 " $\times 5$ " with value of $25.90 \mathrm{~cm}, 1.12$ respectively. The results were similar to Rathore et al. (2004) who showed that large size root trainer $(300 \mathrm{cc})$ produce seedlings with maximum height, collar diameter and dry mass in Casuarina equisetifolia.

The results of vegetatively propagated softwood cuttings treated with IBA at different concentrations viz. 2000, 4000, 6000, 8000 and 10000 ppm and willow leachate of 12 hours, 24 hours and 36 hours in terms of various parameters revealed that the sprouting percent- age showed an increasing trend with increase in concentration of the rooting media from 2000 to $8000 \mathrm{ppm}$ and then decrease with the concentration of $10000 \mathrm{ppm}$ (Table 3). The cuttings treated with IBA @ 8000 ppm showed maximum sprouting percentage (74.50\%) and were at par with $10,000 \mathrm{ppm}(73.75 \%)$. These two concentrations are significantly superior over other concentrations. Regarding the willow leachate the sprouting percentage also showed an increasing trend with increase in concentration of the leachate media from 12 hours to 36 hours. The maximum sprouting percentage $(73.75 \%)$ was shown by the cuttings which were treated with the willow leachate of 36 hours (Plate 3 ).

The rooting percentage followed the same trend as that of sprouting percentage. The rooting percentage differed significantly with increase in concentration from 2000 to $8000 \mathrm{ppm}$ (Table 3). The maximum rooting percentage $(66.75 \%)$ was observed in cuttings treated with IBA @ 8000 ppm followed by cuttings treated with IBA @ 10,000 ppm (65.00\%). The minimum rooting percentage $(20.75 \%)$ was observed in cuttings treated with IBA @ 2000 ppm and no rooting was observed in cuttings under control and willow leachate (Table 3). Root length also showed an increasing trend with increase in concentrations of rooting hormone from 2000 to $8000 \mathrm{ppm}$ and then decrease with the concentration of $10,000 \mathrm{ppm}$. The length of the longest root was $14.65 \mathrm{~cm}$ when the cuttings were treated with 8000 ppm IBA. The average number of roots per cutting in these two levels (8000 and 10,000 ppm IBA) 
was 33.00 and 27.25 respectively. Shoot length also showed an increasing trend with the increase in concentration of rooting hormone from 2000 to $8000 \mathrm{ppm}$ and then decrease with the concentration of 10,000 ppm. The maximum shoot length $(13.90 \mathrm{~cm})$ was observed in cuttings which were treated with $8000 \mathrm{ppm}$ IBA, followed by $10.35 \mathrm{~cm}$ and $9.40 \mathrm{~cm}$ when the cuttings were treated with $6000 \mathrm{pmm}$ and 10,000 ppm IBA respectively. The survival percentage followed similar pattern as that of rooting percentage. The maximum survival percentage $(41.50 \%)$ was shown by cuttings which were treated with 8000 ppm IBA followed by $33.00 \%$ and $27.75 \%$ when the cuttings were treated with $10,000 \mathrm{ppm}$ and $6000 \mathrm{ppm}$ IBA respectively. The minimum survival percentage $(4.50 \%)$ was shown by cuttings which were treated with 2000 ppm IBA.

Thus, all the parameters in vegetative propagation showed an increasing trend with an increase in the concentration of IBA up to $8000 \mathrm{ppm}$ and then showed decreasing trend with further increase in the concentration. The better values at $(6000,8000$ and 10,000 ppm) of sprouting percentage $(73.00 \%, 74.50 \%$ and $73.75 \%)$, rooting percentage $(57.75 \%, 66.75 \%$ and $65.00 \%)$, survival percentage $(27.75 \%, 41.50 \%$ and $33.00 \%)$, length of longest root $(10.67 \mathrm{~cm}, 14.65 \mathrm{~cm}$ and $13.17 \mathrm{~cm})$, number of roots/cutting $(17.25,33.00$ and 27.25$)$ and shoot length $(10.35 \mathrm{~cm}, 13.90 \mathrm{~cm}$ and $9.40 \mathrm{~cm}$ ) are significantly superior over the other concentrations and control as well. Among these three concentrations, $8000 \mathrm{ppm}$ is the best to induce rooting in Himalayan maple (Acer caesium). Thakur and Gupta (1998) reported highest rooting percentage in Alnus nitida using IBA (8000 ppm). The effect of growth regulators on Eucalyptus hybrid was stimulated in root formation (Willson, 1993). Khali and Sharma (2003) reported that IBA was the most suitable hormone, followed by IAA, NAA and $\mathrm{GA}_{3}$ respectively for the induction of higher rooting percentage, number of roots and length of roots in Taxus baccata. The increase in the value of the above mentioned morphological characters due to increase in concentration of IBA might be due to the fact that the hormone hasten the root development which enhances the water and nutrient absorption that in turn promote the growth and development of stem cuttings (Alsup and Cole, 2001). Brock (2014) reported that Caddo (Acer saccharum) and Shantung maples (Acer truncatum) both root best in mound layering situations when treated with 15,000 ppm (1.5\%) IBA. Gangoo et al. (2009) observed that the stem cuttings of Cedrus deodara gave maximum rooting under the treatment of IBA 4000ppm + NAA 4000ppm, Taxus baccata gave maximum rooting when treated with NAA 3000ppm + IBA 2000ppm, Cuppressus torulosa yielded maximum rooting under the treatment IBA 3000 ppm while Pinus wallichiana induced maximum rooting under IBA 2000ppm + NAA 2000ppm.

\section{Conclusion}

The increased market demand and consequent excessive destructive harvesting led to extinction of Himalayan maple (Acer caesium Wall.) in its natural habitats. To facilitate large scale plantations outside the forests, nursery techniques of the species was developed through seed and softwood cuttings. Propagation through seeds was tried with various potting mixture using soil, sand and vermicompost as ingredients in different volume proportions (1:0:0, 1:1:0, 1:1:1, 1:1:2, 2:1:1 and 2:1:2) and container types (polybags of size 7 " $\times 5$ " and root trainer of $300 \mathrm{cc}$ ). The growing medium having soil, sand and vermicompost in the ratio of 2:1:2 performed best with respect to germination percentage, seedling height, collar diameter, shoot weight (fresh/dry), root weight (fresh/dry), shoot: root ratio and survival percentage. Among containers, root trainer $300 \mathrm{cc}$ exhibited maximum germination percentage, collar diameter, fresh shoot weight, dry shoot weight, fresh root weight, dry root weight and survival percentage. Soft cuttings treated with IBA @ 8000 ppm showed maximum sprouting percentage, rooting percentage, length of longest root, no. of roots/ cutting, shoot length and survival percentage. Among willow leachates, maximum sprouting percentage was shown by the cuttings treated with the willow leachate of 36 hours. The study revealed that root trainer of $300 \mathrm{cc}$ filled with potting mixture having soil, sand and vermicompost in the ratio of 2:1:2 is ideal for good quality seedling production of Himalayan maple. Further, IBA @ 8000 ppm or willow leachate of 36 hours are optimum for vegetative propagation through soft cuttings of Acer caesium Wall.

\section{REFERENCES}

Alsup, C.A. and Cole, J.C. (2001). Vegetative propagation and anatomy of root initiation in Acer saccharum 'Caddo' cuttings. Dissertation, Oklahoma State University, Stillwater, Okla.

Alsup, C.M. (2001). Vegetative propagation and anatomy of root initiation in Acer saccharum 'Caddo' stem cuttings. Ph.D. Thesis, Okla. State Univ., Stillwater.

Anonymous (1983). Troup's Silviculture of Indian trees. Vol. III. Controller of Publication, Delhi, India. Anon. (1985). Information on important tree species. FRI \& Colleges, Dehradun, India.

Anonymous (2011). Directorate of Economics and Statistics, District Statistics and Evaluation Office, Baramulla, Jammu and Kashmir.

Atik, A. and Yilmaz, B. (2014). Effects of treatment with vermicompost on the some morphological and physiological characteristics of Scots pine (Pinus sylvestris L.). Eurasian Journal of Soil Science, 3: 42-55.

Bahuguna, V.K., Maithani, G.P., Dhaundiyal, U.D. and Unnikrishna, K.P. (1987). Standardization of nursery techniques of Acacia albida Del. under north Indian moist climatic conditions. Indian Forester, 13: 95-100.

Bhardwaj, S.D, Shamet, G.S., Chauhan, P.S. and Mishra, V.K. (1996). Nursery and plantation technology of 
Chirpine (Pinus roxburghii) under Solan conditions of Himachal Pradesh. Himachal Journal of Agricultural Research, 12(1): 15-21.

Brock, J., Griffin, J. and Boyer, C. (2012). Rooting stem cuttings of woody ornamentals in a cedar amended substrate. Southern Nursery Assoc., 57: 284-286.

Brock, J.A. (2014). Rooting stem cuttings of Shantung maple (Acer truncatum), mound layering shantung and Caddo sugar maples (Acer saccharum) and using eastern red Cedar (Juniperus virginia) as a substrate component in stem cutting propagation. M.Sc. Thesis, Kansas State University, Manhattan, Kansas.

Elfadl, A.M. (2013). Growth performance and physiological characteristics of seedlings of six tropical dry land forest tree species in the Sudan. Journal of Natural Resources and Environmental Studies, 1(2): 25-33.

Gangoo, S.A., Masoodi, N.A., Banyal, R. and Islam, M.A. (2009). Vegetative propagation of four important timber yielding species of Kashmir, The Indian Forester, 135 (12): 1693-1700.

Ghosh, R.C. (1977). Hand book on Afforestation Techniques. Controller of Publication, Delhi, India.

Islam, M.A., Masoodi, T.H., Gangoo, S.A., Sofi, P.A., Bhat, G.M., Wani, A.A., Gatoo, A.A., Singh, A. and Malik, A.R. (2015). Perceptions, attitudes and preferences in agroforestry among rural societies of Kashmir, India. Journal of Applied and Natural Science, 7(2): 976-983.

ISTA (1999). Tropical and Sub-Tropical Tree and Shrub Seed Handbook. International Seed Testing Association, Zurich, Switzerland.

Khali, R.P and Sharma, A.K. (2003). Effect of phytohormones on propagation of Himalayan yew (Taxus baccata L.) through stem cuttings. Indian Forester, 129(2): 289-294.

Luna, R. K. (2005). Plantation Trees. International Book Distributors, Dehradun, India, p-71-74.

Meiners, S.J. (2005). Seed and seedling ecology of Acer saccharum and Acer platanoides: A contrast between native and exotic congeners. Northeastern Naturalist, 12:23-32.

Omokhua, G.E., Ogu, A., and Oyebade, B.A. (2015). Effects of different sowing media on germination and early seedling growth of Terminalia ivorensis (A.Chev.). International Journal of Scientific \& Technology Research, 4(3): 119-122.

Pyarelal and Karnataka, D.C. (1993). Effect of orientation, sowing and soil mixture on germination behavior of Quercus leucotrichophora. Indian Forester, 119: 112-125.

Rathore, T.S., Annapurna, D., Joshi, G. and Srivastava, A. (2004). Studies on potting and size of container on the quality of seedling production in Casuarina equisetifolia Forest. Indian Forester, 130(3): 323-332.

Roussy, A.M. (2014). The Sexual and vegetative propagation of sugar Maple and its threat from Norway Maple. Ph.D. Thesis, School of Environmental Science, Guelph, Ontario, Canada.

Srivastava, R., Nanhorya, R. and Upadhyaya, J.K. (1998). Selection of proper potting mixture for root trainer of Eucalyptus hybrid. Indian Forester, 124: 502-510.

Sofi, P.A. and Bharadwaj, S.D. (2007). Standardization of potting media and root trainer size for production of quality seedling of Cedrus deodara Roxb. G. Don. (D. Don). SKUAST Journal of Research, 9: 24-28.

Starr, Z.W. (2011). Evaluation of eastern red cedar as a substrate for container grown plant production. M.Sc. Thesis, Kans. State Univ., Manhattan.

Thakur, I.K. and Gupta, R. (1998). Effect of auxins on rooting of Alnus nitida Endl. cuttings. Indian Journal of Forestry, 21(2): 174-175.

Van Geldern, D.M., Oterdoom, H.J. and De Jong, P.C. 2010. Maples of the World. Timber Press, Portland, Oregon.

Willson, M.F. 1993. On the costs of reproduction in plants. Acer negundo, Amer. Midl. Natural, 115(1): 204-207. 